\title{
Tannin-caprolactam and Tannin-PEG formulations as outdoor wood preservatives: biological properties
}

\author{
Jinbo Hu ${ }^{1,2} \cdot$ Marie-France Thevenon $^{2} \cdot$ Sabrina Palanti $^{3} \cdot$ Gianluca Tondi $^{4}$
}

Received: 7 August 2016/Accepted: 21 October 2016/Published online: 15 February 2017

(C) The Author(s) 2017. This article is published with open access at Springerlink.com

\begin{abstract}
- Key Message This article presents the enhancement in boron fixation as well as the improved biological resistance against fungi and termites for wood samples treated with tannin-caprolactam and tannin-PEG formulations.

- Context Although the recently developed tannin-boron wood preservatives have shown high biological protection, they presented also average resistance against weathering. The tannin-caprolactam formulations have shown improved weathering resistances and dimensional stability.

- Aims For this reason, more detailed biological tests were performed to evaluate the influence of the caprolactam and PEG on the biological resistance.

- Methods In this paper, the boron leaching of the tannincaprolactam and tannin-PEG impregnated Scots pine specimens was observed and the biocidal effect against fungi
\end{abstract}

Contribution of the co-authors Jinbo Hu: Sample preparation and data collection. Co-corresponding author

Marie-France Thevenon: Research leader, publication writing and biological tests

Sabrina Palanti: Test with the Hylotrupes bajulus

Gianluca Tondi: Research leader, formulation developer, publication writing and data analysis. Main Corresponding author

Handling Editor: Jean-Michel Leban

Jinbo $\mathrm{Hu}$

hjb1999@hotmail.com

Gianluca Tondi

gianluca.tondi@fh-salzburg.ac.at

Marie-France Thevenon

marie-france.thevenon@cirad.fr

Sabrina Palanti

palanti@ivalsa.cnr.it
(Antrodia spp. and Coniophora puteana) and insects (Reticulitermes flavipes and Hylotrupes bajulus) were determined according to the guidelines of EN 113, EN 117, and EN 47.

- Results The advanced formulations containing PEG have shown interesting resistance against fungal decay, but very low penetration and weak resistance against larvae while the tannin-caprolactam preservatives have shown overall improved biological performances and higher boron fixations.

- Conclusion The biocidal activity of the caprolactam-added formulations was overall enhanced and therefore these formulations are confirmed to be an interesting alternative for the wood preservation in outdoor environment.

Keywords Condensed tannins $\cdot$ Caprolactam $\cdot$ Boron leaching $\cdot$ Fungal decay $\cdot$ Insect resistance

\section{Introduction}

Most of the European temperate wood species are low to moderately durable when exposed outdoor and therefore susceptible to degradation, including biological attacks and weathering. Therefore, the use of preservative agents is a

College of Material Science and Engineering, Central South University of Forestry and Technology, Shaoshan South Road, No. 498, Changsha 410018, China

2 Wood Preservation Laboratory, CIRAD, UPR BioWooEB, TA B 114/16, 73 rue Jean-François Breton, Montpellier Cedex 5 34398, France

3 CNR - IVALSA, Via Madonna del Piano, 1050019 Sesto Fiorentino, Italy

4 Forest Product Technology and Timber Construction Department, Salzburg University of Applied Sciences, Marktstraße 136a, 5431 Kuchl, Austria 
crucial factor to extend the service life of such timber in exterior environmental conditions. With the development of wood-use/wood utilization and chemical industry, various formulations have been applied to prevent degradation of nondurable wood products. Since over a decade, formulations such as pentachlorophenol (PCP), creosote, and copper chromium arsenate (CCA) have been highly restricted or banned due to their ascertained environmental and/or human toxicity (Hiemstra et al. 2007; Hopp et al. 2008; Zheng et al. 2011). Non-metallic water-borne boron formulations have a long history as wood preservatives, as well as a broad range of activity against decay fungi and insects in protected above ground contact situations (Williams and Amburgey 1985; Drysdale 1994; Thevenon et al. 1997). Boron compounds for wood protection are highly effective for stand-alone formulations as well as associated to other active ingredients for more complex formulations where they act as a co-biocide (Freeman et al. 2009). Nevertheless, using boron compounds means facing some problems: (i) from a technical viewpoint, boron compounds remain leachable from treated timber due to their high solubility, and (ii) despite a favorable environmental profile, boron compounds have seen their use restricted by the European Commission (i.e., maximum use concentration under regulation) (98/8/EC 2008). Thus, the key issue to extend boron preservatives' use for wood protection appears to be their fixation at low levels into the wood (Obanda et al. 2008).

The efficacy of tannin-boron preservatives to protect wood against degrading fungi and insects was recently studied in order to develop environmentally friendly wood preservatives (Thevenon et al. 2009). These formulations presented the innovation of being able to stabilize boron in wood. The mechanism of tannin-boron formulation is as following: under alkaline conditions the condensed tannin of mimosa reacts with the intermediate species formed by decomposition of hexamine to result in no or extremely low formaldehyde emission (Pichelin et al. 1999). Furthermore, the boric acid was added in the formulation and stabilized during the polymerization of the condensed tannin molecules. This anchoring mechanism includes also possible covalent bonding between the borate and the flavonoid network (Tondi et al. 2012a). Notwithstanding it, at least one hydroxyl group of boric acid remains free and results active against the biologic attacks (Lloyd 1993; Lloyd 1998). These innovative wood preservatives were intensively studied for their fungicidal as well as for their mechanical and fire resistance properties, and they showed generally outstanding features (Thévenon et al. 2010; Tondi et al. 2012b, 2013a, 2014). However, these formulations have encountered the drawback when the treated wood specimens are exposed to aggressive leaching and weathering (Tondi et al. 2012b, 2013b).

In the present study, two types of approaches were considered to modify the standard tannin-boron formulation: (1) blending the tannin resin with an unreactive polyether such as polyethylene glycol (PEG) to decrease the amount of crosslinks in the hardened network due to its steric hindrance and (2) covalently combining the tannin oligomers with molecule such as caprolactam to produce a more linear copolymer (Pizzi 1994). The use of these template molecules in the synthesis of the new formulations improved the weathering resistance (Tondi et al. 2016), and therefore they were investigated also for their biologic resistance.

\section{Materials and methods}

\subsection{Preparation of treatment solution}

Mimosa (Acacia mearnsii) tannin extract was supplied by Silva Chimica (Cuneo, Italy), and hexamethylentetramine (hexamine), boric acid, sodium hydroxide, caprolactam, and polyethylene glycol (PEG) were provided by Sigma-Aldrich. The formulations were prepared dissolving the mimosa extract in a water solution containing boric acid and $\mathrm{NaOH}$. PEG or caprolactam were added and the formulation and the $\mathrm{pH}$ of the solution were corrected to 9.0 with $\mathrm{NaOH}$ solution $(33 \% \mathrm{w} / \mathrm{w})$. Finally, $6 \%$ of hexamine (w/w tannin) was successively added and stirred until homogeneity. The exact formulation compositions for each treatment are reported in Table 1. The formulations containing caprolactam and PEG will be named "advanced" tannin-boron formulation, in contrast to "standard" tannin-boron formulations (Tondi et al. 2012c).

\subsection{Impregnation of wood blocks}

Wood samples of $50 \times 25 \times 15 \mathrm{~mm}^{3}(\mathrm{~L}, \mathrm{R}, \mathrm{T})$ were cut from conditioned sapwood portions of Scots pine (Pinus sylvestris L.). The samples were successively oven-dried at $103{ }^{\circ} \mathrm{C}$ until constant weight (Mo) prior to impregnation. All treatments were performed using a single vacuum pressure impregnation. In the treatments, the vacuum cycles consisted of $30 \mathrm{~min}$ at $8 \mathrm{mbar}$ in a desiccator. Then, the pressure was slowly increased up to ambient pressure and the specimens were kept in the impregnation solution for $24 \mathrm{~h}$. The samples were then removed from the solution and the excess liquid from their faces was blotted with filter paper before registering the wet weight of the sample $(\mathrm{Mw})$.

The impregnated specimens were, then, kept $16 \mathrm{~h}$ at $103^{\circ} \mathrm{C}$ in a ventilated oven so that the resin could harden. The impregnated wood blocks were weighed after the dry (Md) and finally reconditioned at $20{ }^{\circ} \mathrm{C}$ and $65 \% \mathrm{RH}$ for 2 weeks before undergoing the biological tests.

Wet $(\mathrm{Rw})$ and dry $(\mathrm{Rd})$ retentions of the solution and of the solid preservative on wood blocks $\left(\mathrm{kg} / \mathrm{m}^{3}\right)$ was calculated based on the following equations.

$\mathrm{Rw}=\frac{(\mathrm{Mw}-\mathrm{Mo})}{V}$ 
Table 1 Percentage by weight of substances used for the preparation of the tannin-based wood preservatives

\begin{tabular}{lllllll}
\hline Formulation & $\begin{array}{l}\text { Tannin } \\
(\%)\end{array}$ & $\begin{array}{l}\text { Boric acid } \\
(\%)\end{array}$ & $\begin{array}{l}\text { Hexamine } \\
(\%)\end{array}$ & $\begin{array}{l}\mathrm{NaOH} \\
(\%)\end{array}$ & $\begin{array}{l}\text { Additive } \\
(\%)\end{array}$ & $\begin{array}{l}\text { Water } \\
(\%)\end{array}$ \\
\hline Pure boric acid & - & 0.43 & - & - & - & 99.57 \\
Tannin-boron 10\% & 9.73 & 0.49 & 0.58 & 0.49 & - & 88.72 \\
Tannin-boron 20\% & 19.12 & 0.96 & 1.15 & 0.96 & - & 77.82 \\
Tannin-caprolactam-boron & 8.14 & 0.41 & 0.49 & 0.41 & 15.56 & 75.01 \\
Tannin-PEG-boron & 9.72 & 0.49 & 0.58 & 0.49 & 19.41 & 69.34 \\
\hline
\end{tabular}

$\mathrm{Rd}=\frac{(\mathrm{Md}-\mathrm{Mo})}{V}$

In these equations, Mo: dry weight before treatment $(\mathrm{kg})$, Mw: wet weight after treatment $(\mathrm{kg}), \mathrm{Md}$ : dry weight after treatment and resin hardening. $V$ : volume of wood blocks $\left(\mathrm{m}^{3}\right)$. The retention of the single components was calculated by multiplying the wet retentions times the concentration expressed in percent by weight of Table 1 . At least 50 specimens for formulation were impregnated and the retentions are calculated as average value.

\subsection{Leaching procedure}

The boron leaching in the specimens was performed according to two guidelines: EN 84 (1997) or NF X 41-569 (2014). The leaching waters were collected and conserved at $4{ }^{\circ} \mathrm{C}$ after each step during leaching for further analyses.

The 12 samples per formulation prepared for the biological resistance tests were also leached according to EN 84 and NF X 41-569 in order to evaluate the impact of leaching system on the performances of the formulations.

\subsection{Analysis of boron in the leachate}

The leaching waters derived from the NF X 41-569 procedure were analyzed with an Agilent 4100 Microwave PlasmaAtomic Emission Spectrometer (MP-AES).

The solutions were nebulized in a chamber with cyclonic double pass, and the AES was set for detecting the emission at the wave length of $249.7 \mathrm{~nm}$ with a read and stabilization time of 3 and $20 \mathrm{~s}$, respectively.

The collected boron concentration allowed calculating the degree of boron fixation which was calculated according to following equation:

$$
B(r)(\%)=\frac{B o-B 1}{B o} \times 100
$$

In this equation, $B(r)$ is boron degree of fixation (\%), $B_{0}$ is the average uptake of boron $\left(\mathrm{kg} / \mathrm{m}^{3}\right), B_{1}$ is the leached out boron in solution related to the amount of wood $\left(\mathrm{kg} / \mathrm{m}^{3}\right)$.

\subsection{Biologic resistance tests}

\subsubsection{Fungal decay resistance test}

Decay tests were conducted according to the method given in EN 113 (1996) using only two brown-rot fungi, Coniophora puteana (temperate strain Bam Ebw 15) and Antrodia spp. (tropical strain CTFT 57A). If C. puteana is mandatory in EN113 test, Antrodia is not, but this tropical strain has been shown to be very discriminant (Kokutse et al. 2006; Niamké et al. 2011) due to its virulence when in tropical conditions.

Sterile culture medium $(65 \mathrm{ml})$, prepared from malt $(40 \mathrm{~g})$ and agar $(20 \mathrm{~g})$ in distilled water (1 1), was placed in a culture flask, inoculated with two small pieces of freshly grown pure mycelium and incubated for 2 weeks to allow full colonization of the medium by the mycelium. Tested blocks were sterilized by gamma radiation after measuring their oven-dried weights (Mi). Two blocks (one treated and one control) were placed directly on malt agar medium in each culture flask under sterile conditions. Incubation of Antrodia sp. and C. puteana were respectively carried out at $27^{\circ} \mathrm{C}, 75 \% \mathrm{HR}$ and $22^{\circ} \mathrm{C}, 70 \% \mathrm{RH}$ in a climatic chamber for 16 weeks. Six replicates per treatment were exposed to the fungi. Once the fungal exposure was over, wood blocks were carefully brushed, dried at $103^{\circ} \mathrm{C}$ and weighed (Mf). Controls used along with the treated samples, and virulence controls (six samples) were untreated pine sapwood samples. The extent of the fungal attack was determined based on the percentage of mass loss. Weight loss $\left(W_{\mathrm{L}}\right)$ was expressed as a percentage of the initial oven-dried weight of the sample according to the formula:

$W_{\mathrm{L}}(\%)=\frac{\mathrm{Mi}-\mathrm{Mf}}{\mathrm{Mi}} \times 100 \%$

In this equation, $\mathrm{Mi}(\mathrm{g})$ and $\mathrm{Mf}(\mathrm{g})$ are the initial and final dried mass of the samples before and after exposure to fungus, respectively.

\subsubsection{Termite resistance test}

A laboratory non-choice test was carried out according to the testing procedure described in the EN 117 (2013) standard. In a flask containing an adequate quantity of moistened sand (1 
vol. water $/ 4 \mathrm{vol}$. sand), a glass ring was placed in the middle of its vertical walls of the test container along with a group of Reticulitermes flavipes (ex. santonensis) termites (250 workers, three soldiers, and three nymphs). The flasks were placed in a climatic room $\left(27^{\circ} \mathrm{C}, 75 \% \mathrm{RH}\right)$ for $48 \mathrm{~h}$ in order to ensure that the termites had settled properly. Then, each treated wood specimen was carefully placed on the glass ring. One of the narrow longitudinal sides was resting on the ring with a wide longitudinal side in contact with one of the test container walls. Test assemblies were kept in the conditioned chamber $\left(27{ }^{\circ} \mathrm{C}, 75 \% \mathrm{RH}\right)$ for 8 weeks. Six replicates per treatment were exposed to the termites. Observations were carried out on a weekly basis in order to add water and verify the development of the attacks. In order to validate the test, a control was necessary using three untreated specimens of pine sapwood. At the end of the test, samples were removed from the flask, air-dried, and a visual rating was given according to the criteria of EN117. The survival rate of the termites was quantified. Moreover, samples were dried to anhydrous weight $\left(M_{3}\right)$. Results were expressed as percentage of weight loss $\left(W_{\mathrm{L}}\right)$ of samples due to termite attacks after 8 weeks using Eq. (4). In this equation, $M_{2}$ (g) and $M_{3}(\mathrm{~g})$ are the oven-dry weight of the sample before and after the termite attack, respectively.

\subsubsection{Resistance towards Hylotrupes bajulus larvae}

The treated wood specimens have been tested for their resistance towards larvae of Hylotrupes bajulus according to EN 47 (2005). Five samples were selected for each formulation. Six holes, approximately $3 \mathrm{~mm}$ deep, were made in a diagonal pattern on the upper longitudinal face of each test sample. A newly hatched larva of $H$. bajulus (category 1 ) was carefully inserted head first in each hole. The specimens were put in a testing chamber at $22{ }^{\circ} \mathrm{C}$ and $70 \% \mathrm{RH}$ for 4 weeks and the survival of the larvae was then examined by means of X-rays. This technique allows determining the digging activity of the larvae so that the efficacy of the wood preservatives can be estimated.

\section{Results}

\subsection{Retentions}

The wet and the dry retentions of the Scots pine specimens treated with the five wood preservatives are reported in Fig. 1.

It can be observed that the samples containing $20 \%$ tannin are the ones in which the solution penetrates the least due to their high viscosity (Tondi et al. 2013a). However, the dry retention remains very high. The formulations containing caprolactam or PEG show similar behavior of more concentrated solutions: a slightly lower wet retention and a slightly higher dry retention due to the increase of the solid content of the two formulations.

More quantitative information can be obtained reporting the retentions in kilogram per cubic meter (Table 2).

This limited amount of boron retained is perfectly fitting with the requirement of the directive $98 / 08 / \mathrm{EC}$ which allows up to $5.5 \%(\mathrm{~m} / \mathrm{m})$ of boric acid in relation to dry wood. In our worst case, around $6.7 \mathrm{~kg} / \mathrm{m}^{3}$ of boric acid are used, and considering the density of air-dried pine can be considered around $400 \mathrm{~kg} / \mathrm{m}^{3}$, the amount of boric acid in will be, on average, close to $1.7 \%(\mathrm{~m} / \mathrm{m})$.
Fig. 1 Wet and dry retention in kilogram per cubic meter of the different formulations

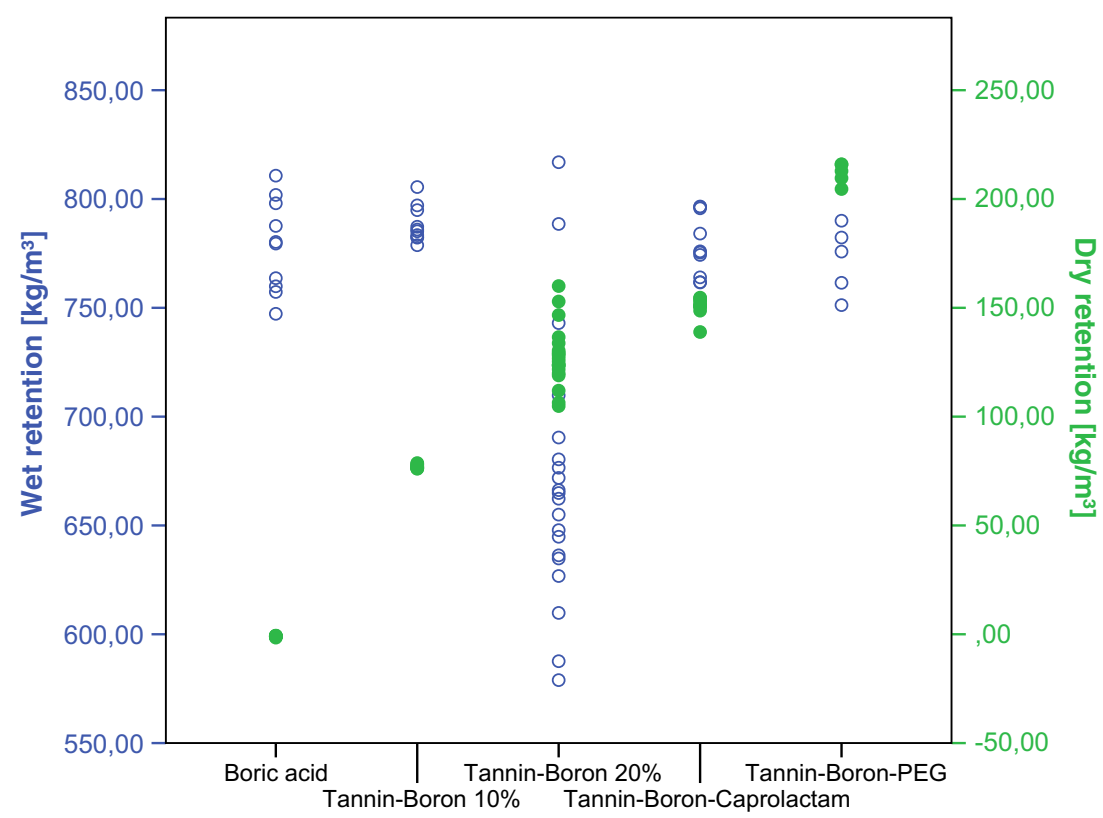


Table 2 Retentions of the single components in the 5 formulations

\begin{tabular}{lllll}
\hline Formulation & $\begin{array}{l}\text { Wet retention } \\
\left(\mathrm{kg} / \mathrm{m}^{3}\right)(\mathrm{SD} \%)\end{array}$ & $\begin{array}{l}\text { Dry retention } \\
\left(\mathrm{kg} / \mathrm{m}^{3}\right)(\mathrm{SD} \%)\end{array}$ & $\begin{array}{l}\text { Tannin retention } \\
\left(\mathrm{kg} / \mathrm{m}^{3}\right)\end{array}$ & $\begin{array}{l}\text { Boron } \\
\text { retention }\left(\mathrm{kg} / \mathrm{m}^{3}\right)\end{array}$ \\
\hline Free boric acid & $778.61(2.58)$ & -0.94 & - & 0.592 \\
Tannin-boron 10\% & $788.28(1.00)$ & $77.11(1.12)$ & 76.70 & 0.684 \\
Tannin-boron 20\% & $669.63(8.68)$ & $127.66(10.53)$ & 128.03 & 1.138 \\
Caprolactam-tannin-boron & $772.18(1.82)$ & $211.76(2.02)$ & 62.85 & 0.560 \\
PEG-tannin-boron & $778.59(1.71)$ & $150.63(2.86)$ & 75.68 & 0.675 \\
\hline
\end{tabular}

\subsection{Leaching behavior}

One of the most important aspects to be monitored for the advanced tannin-based wood preservatives is their behavior against leaching. It was previously observed by Tondi et al. (2012a) that the network of tannin was able to considerably protect the boron from leaching. For this reason, the introduction of additives in the formulation does not ensure that the polymerization maintains the fixation of boron during leaching. Therefore, the leaching tests according to NF X 41-569 guidelines were performed and the leaching waters underwent to MP-AES measurement to determine the amount of boron released all over these tests.

The percentage of boron leached during the test is reported in Fig. 2.

The presence of tannin network significantly hinders the leaching of boron. In particular, the formulation containing caprolactam stabilizes the boron around $50 \%$ better than the standard tannin-based wood preservatives.

This observation suggests that the polymerization of tannin and hexamine includes actively the caprolactam in the network and the boron fixation results even enhanced.
These results underline that the tannin-boron-caprolactam treatments may supply lasting protection against wood degradation in outdoor exposures.

When these data are compared with the loss of tannin during the leaching (Tondi et al. 2016), it can be observed that the after $10 \mathrm{~h}$ around $10 \%$ of boron was lost and after $80 \mathrm{~h}$ around $20 \%$, while the tannin loss after $10 \mathrm{~h}$ is around $5 \%$ while the loss in $80 \mathrm{~h}$ is around $10 \%$. This scenario can have two explanations: (i) Not all the boric acid molecules combines with the tannin and therefore they are leached quickly or (ii) the boric acid combine with the tannin completely, but the tannin oligomers fractions carrying too much boric acid do not polymerize completely and therefore they remain soluble.

\subsection{Biological decay}

The decay resistances of the treated specimens are given in Fig. 3 for Antrodia spp. and Fig.4 for C. puteana.

For both fungal strains, the virulence controls present a mass loss above $20 \%$ as required by the EN113 standard, allowing then to validate the tests. Each control associated with a treated sample (in the same culture flask) also presented a mass loss above $20 \%$ (data not shown).
Fig. 2 Amount of boron leached for pine sample treated with advanced and standard tanninbased wood preservative (20\% tannin) and a water solution of boric acid

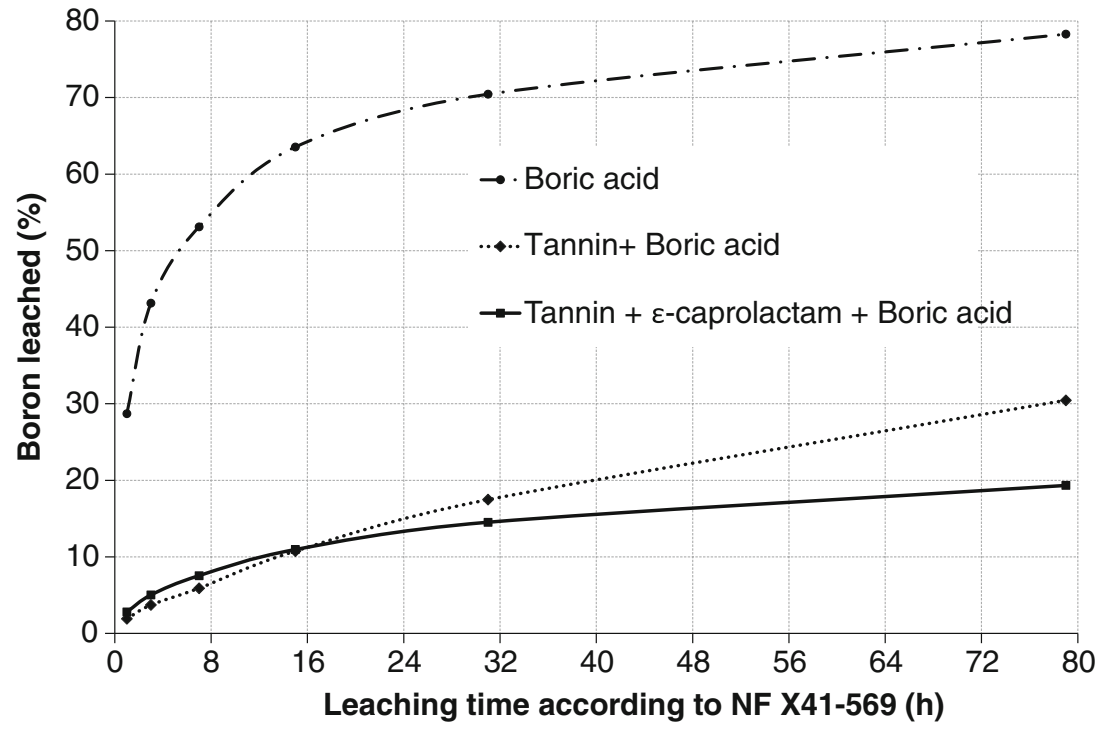


Fig. 3 Decay resistance (mean weight loss (standard deviation) $\%$ ) of wood treated with different tannin-boron formulations exposed to Antrodia spp

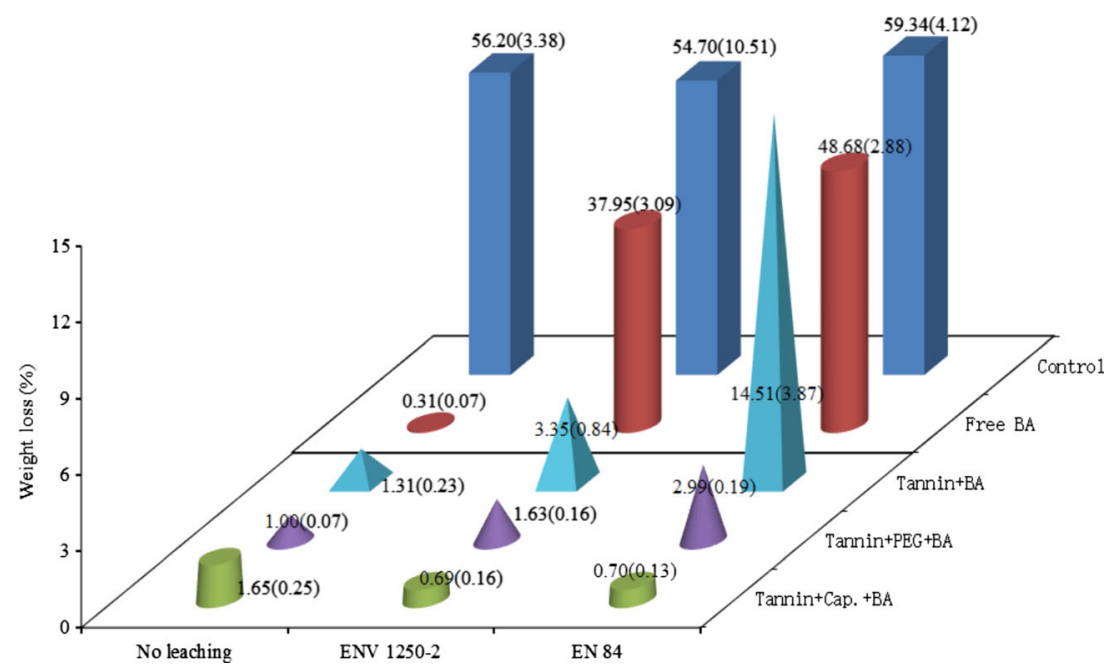

For boric acid alone, as expected, the same trend in behavior is observed for both fungal strains. Unleached free boric acid provides an excellent protection to the treated wood. Being readily leachable, boric acid alone is most probably completely leached after EN84 as weight losses of treated blocks are comparable to control ones. Even if a slight amount of boric acid remains into the wood after NF X 41-569, and a small effect is noticeable towards Coniophora, the boron content is far from the fungitoxic threshold.

The efficacy of the tannin-boron formulation (without any additive) is very significant compared to boron alone, especially after leaching. For both the leaching tests done, the formulation containing boron, offer much better performances. However, it appears that these formulations cannot meet the requirements of the EN113 (mass loss below 3\%) after a leaching according to EN84. These results are in agreement with the previous studies of Thevenon et al. (2009) and Tondi et al. (2012a).

Tannin-boron formulations including caprolactam or PEG provide an improved protection to the treated wood, even after leaching. The standard deviations associated to these mass loss results are rather small, which is in favor of a homogenous treatment and behavior. Despite inducing interesting performances to the tannin-boron treatment, PEG leads to wooden blocks with very gelatinous surfaces (Tondi et al. 2016). This phenomenon inhibits any further development of the formulation.

The advanced formulations containing caprolactam showed the smallest amount of boron after the treatment, and, the highest resistance to Antrodia attacks even after the aggressive EN84 leaching.

The efficacy of these associations are due to the amount of boron left into the wood, as well as to a possible limited effect of tannin, as caprolactam is not reported to be fungitoxic or fungistatic, nor environmentally problematic (Ash and Ash 2004; Negoro 2004). Moreover, the nitrogen contained with the caprolactam molecule does not promote fungal decay (Ouchiyama et al. 1993). It can be observed that boron is still acting as fungistatic also in combination with other molecules (Lloyd 1998).
Fig. 4 Decay resistance (mean weight loss (standard deviation) $\%)$ of wood treated with different tannin-boron formulations exposed to Coniophora puteana

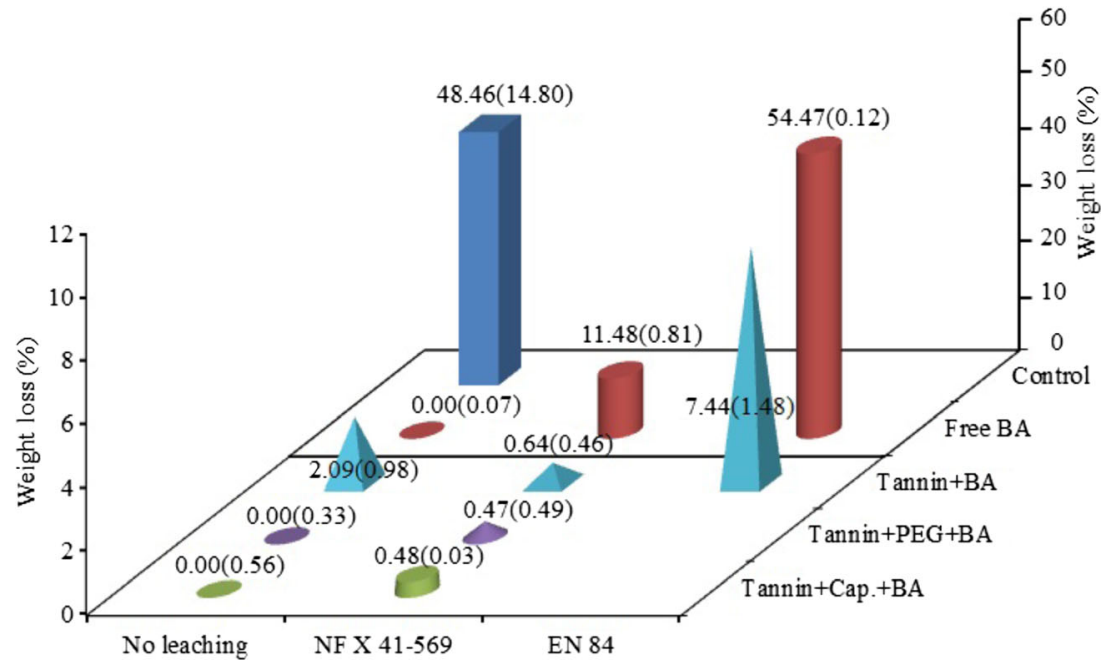


Table 3 Performance of the different tannin-based preservatives against termites

\begin{tabular}{|c|c|c|c|c|c|c|c|c|}
\hline \multirow[t]{2}{*}{ Formulation } & \multirow[t]{2}{*}{ Leaching } & \multirow{2}{*}{$\begin{array}{l}\text { Mean worker survival } \\
\text { rate }(\%)(\mathrm{SD})\end{array}$} & \multirow{2}{*}{$\begin{array}{l}\text { Mean weight } \\
\text { loss }(\%)(\mathrm{SD})\end{array}$} & \multicolumn{5}{|c|}{ Repartition of the sample in each visual rating class (\%) } \\
\hline & & & & 0 & 1 & 2 & 3 & 4 \\
\hline Control & - & $71.82(9.18)$ & $10.22(1.05)$ & 0 & 0 & 0 & 0 & 100 \\
\hline \multirow[t]{3}{*}{ Pure boric acid } & Unleached & 0 & $1.54(2.16)$ & 16.7 & 83.3 & 0 & 0 & 0 \\
\hline & NF X 41-569 & 0 & $2.31(1.72)$ & 0 & 0 & 0 & 50.0 & 50.0 \\
\hline & EN 84 & $55.47(7.95)$ & $11.33(3.45)$ & 0 & 0 & 0 & 0 & 100 \\
\hline \multirow[t]{2}{*}{ Tannin-boron } & Unleached & 0 & $2.4(0.4)$ & 0 & 100 & 0 & 0 & 0 \\
\hline & NF X 41-569 & 0 & $1.5(0.1)$ & 0 & 0 & 100 & 0 & 0 \\
\hline \multirow[t]{3}{*}{ Tannin-boron-caprolactam } & Unleached & 0 & $1.45(0.16)$ & 50.0 & 50.0 & 0 & 0 & 0 \\
\hline & NF X 41-569 & 0 & $0.65(0.31)$ & 0 & 50.0 & 50.0 & 0 & 0 \\
\hline & EN 84 & 0 & $1.92(0.23)$ & 0 & 0 & 0 & 83.3 & 16.7 \\
\hline
\end{tabular}

\subsubsection{Termites resistance}

The termite resistance of untreated/treated specimens was tested according to EN 117 and the results are presented in Table 3.

The controls specimens present a strong degradation (visual rating 4) and the survival of the termite workers is above $50 \%$, which allows to validate the test.

Again, as expected, unleached boric acid alone protect the wood samples from termite attack. EN84 procedure leaches out boron alone and the resulting performance of such samples are similar to control samples. NF X 41-569 seems to keep enough boron to kill the termites, but not to insure a protective effect efficient enough, visual rating being of 4 .

Conversely, the tannin-boron-caprolactam formulation contains enough boron after leaching to kill the termites. However, boron compounds are not acting as repellent not even when in combination with tannin polymers, so the termites do have to ingest some treated wood before dying (Grace et al. 1992). Thus, even if mass losses of wood exposed 8 weeks to termites is low and comparable to what is obtained with unleached free boric acid, visual rating are classifying the treatment as not efficient enough.

\subsubsection{Resistance against Hylotrupes bajulus larvae}

The advanced tannin-based formulations containing PEG and caprolactam have been also tested against Hylotrupes bajulus larvae and the results are synthesized in Table 4.

The most evident observation is that the formulations in which caprolactam is used, offers the higher biocidal properties. All the larvae that begin tunneling, die before the end of the normative test. Good results were obtained also for the standard tannin-based formulation especially when the leaching conditions were not so drastic. In this test, very negative performance has been offered by the advanced formulation containing PEG. The high survival rate after tunneling suggests that the penetration of tannin and boron in the inner layers of the sample is very limited. Therefore, being the inoculation already a few millimeters under the surface of the specimens, the concentration of the boron at that deep could be already too low to provide sufficient protection.
Table 4 Behavior of tanninboron advanced formulations against Hylotrupes bajulus larvae

\begin{tabular}{lllll}
\hline Formulation & Leaching & $\begin{array}{l}\text { Surviving larvae } \\
\text { before tunneling }(\%)\end{array}$ & $\begin{array}{l}\text { Surviving larvae } \\
\text { after tunneling (\%) }\end{array}$ & $\begin{array}{l}\text { Total surviving } \\
\text { larvae }(\%)\end{array}$ \\
\hline Control & Unleached & 63.3 & 68.4 & 43.3 \\
Tannin-boron & Unleached & 73.3 & 4.5 & 3.3 \\
& NF X 41-569 & 90.0 & 11.1 & 10.0 \\
Tannin-boron-PEG & EN 84 & 90.0 & 33.3 & 30.0 \\
& Unleached & 96.7 & 27.6 & 26.7 \\
Tannin-boron-caprolactam & NF X 41-569 & 76.7 & 52.2 & 40.0 \\
& Unleached & 60.0 & 0.0 & 0.0 \\
& NF X 41-569 & 100.0 & 0.0 & 0.0 \\
\hline
\end{tabular}




\section{Discussions}

The advanced tannin-based formulations have shown very different results: on one hand, the PEG containing blending had mainly negative properties that allows to conclude that this mixed formulation do not deserve to be further investigated. On the other hand, the caprolactam formulations have shown very interesting improvements.

The PEG is a long chain of relatively inert polymer that does not copolymerizes with the tannin-hexamine. The presence of this molecule involves an increase of viscosity of the wood preservative and this carries to lower penetration of the solution. The molecule of PEG will also hinder the tannin molecules to penetrate due to their high molecular mass and their low chemical affinity. The samples treated with PEG modified tannin solutions have a very viscous surface after the impregnation step and the molecules of PEG that initially are penetrated in the wood structure, and come out again when the sample is leached in water. Despite this significant drawback, the formulation shows still good preservation properties against fungi, but it does not give enough protection against insect attacks.

The tannin formulation added of caprolactam, conversely, presents much better features. The appearance of the sample as well as the penetration does not modify much from the standard tannin-boron formulation.

These aspects could be due to the copolymerization of the tannin-hexamine with the molecule of caprolactam, but it can also be that the monomers of caprolactam produce some fragment of PA-6 (polyamide, namely Nylon 6), which are chemically compatible to the polymer of tannin, and so they can participate to the wood protection. However, there is a high probability that the networks are interconnected because the aspect of the treated samples appears very homogeneous, and the FT-IR and the ${ }^{13} \mathrm{C}$-NMR investigations show evidences of covalent chemical bonding. The theory of having a new copolymer was an expectation because the tannin-caprolactam formulations present improved properties against leaching that involve also to enhanced performances against fungi and insects. The lower boron loss during leaching can be consequently due also to the reinforcement of the tannin network and not only to the covalent fixation of boron.

\section{Conclusions}

PEG and caprolactam were added to the standard tanninboron formulation in order to produce a more elastic polymer that could resist the continuous dimensional movement of the wood when exposed outdoor. It was proved that PEG does not help this process because it produces a blend that hinders the penetration, increases the sensibility to water leaching, and worsens the overall features of the tannin-based formulations.
Contrarily, the addition of caprolactam allows to obtain more elastic copolymers that warrant a better leaching resistance and consequent better stabilization of boron. However, this enhancement of fixation does not hinder the wood preservative to maintain the efficacy against biological attacks. Not only the boron leaching decreases of around $50 \%$, but the efficacy against fungi and insects improves significantly carrying to results that overcome the EN 113 and EN 117 specifications almost for every leaching condition. The new wood preservative does not pass the standard after EN 84 leaching, but the results obtained show that the addition of some repulsive agent will complete the formulation. Future studies will focus on replacing the caprolactam with more natural polyamides.

Acknowledgements Open access funding provided by FH Salzburg University of Applied Sciences. The authors gratefully acknowledge the support of the ERA-Net wood-wisdom program for the project "Biocopol - enhancing wood durability and physical properties through innovative bio-based sustainable treatments" as well as the ANR-10EQPX-16-Xyloforest for funding. Dr. Jinbo HU acknowledges to the supports, which are provided by Scientific Research Fund of Hunan Provincial Education Department (16B281) and Scientific Research Foundation for High-level Personnel of Central South University of Forestry and Technology (2015YJ023) in China.

\section{Compliance with ethical standards}

Funding The study was financed for one part by the European Union with the ERA-Net wood-wisdom program with the project "BioCoPolenhancing wood durability and physical properties through innovative bio-based sustainable treatments" and one part was supported by the French funding agency ANR-10-EQPX-16-Xyloforest.

Open Access This article is distributed under the terms of the Creative Commons Attribution 4.0 International License (http:// creativecommons.org/licenses/by/4.0/), which permits unrestricted use, distribution, and reproduction in any medium, provided you give appropriate credit to the original author(s) and the source, provide a link to the Creative Commons license, and indicate if changes were made.

\section{References}

98/8/EC (2008) Directive of the European Parliament and of the Council concerning the placing of biocidal products on the market

Ash M, Ash I (2004) Handbook of wood preservatives. Synapse Information Resource Inc, ISBN 1-890595-66-7: 795

Drysdale JA (1994) Boron treatments for the preservation of wood: a review of efficacy data for fungi and termites. IRG/WP 94-30037. Stockholm, Sweden

EN 47 (2005) Wood preservatives. Determination of the toxic values against larvae of Hylotrupes bajulus

EN 84 (1997) Wood preservatives. Accelerated ageing of treated prior to biological testing. leaching procedure

EN113 (1996) Wood preservatives. Method for determining the protective effectiveness against wood destroying Basidiomycetes. Determination of toxic values 
EN 117 (2013) Wood preservatives. Determination of toxic values against Reticulitermes species (European termites)

Freeman MH, McIntyre CR, Jackson D (2009) A critical and comprehensive review of boron in wood preservation. Proc, Am Wood Prot Assoc-AWPA 105:279-294

Grace JK, Yamamoto RT, Tamashiro M (1992) Resistance of boratetreated Douglas-fir to the Formosan subterranean termite. Forest Prod J 42:61-65

Hiemstra TF, Bellamy CO, Hughes JH (2007) Coal tar creosote abuse by vapour inhalation presenting with renal impairment and neurotoxicity: a case report. J Med Case Rep 1:102

Hopp L, Nico PS, Marcus MA, Peiffer S (2008) Arsenic and chromium partitioning in a podzolic soil contaminated by chromated copper arsenate. Environ Sci technol 42:6481-6486

Kokutse A, Stokes A, Bailleres H, Koukou K, Baudasse C (2006) Decay resistance of Togolese (Tectona grandis L.f) heartwood and relationship with colour. Trees-Struct Funct 20:219-223

Lloyd JD (1993) The mechanisms of action of boron-containing wood preservatives, Biology, Phd Thesis, Imperial college, London, UK

Lloyd JD (1998) Borates and their biological applications. IRG/WP 9830178. IRG Secretariat, Stockholm, Sweden

Negoro S. (2004) Biodegradation of nylon and other synthetic polyamides, in miscellaneous biopolymers, biodegradation of synthetic polymers, Wiley edition, 9: 395-409

NF X 41-569 (2014) Wood preservatives-laboratory method for obtaining samples for analysis to measure losses by leaching into water or synthetic water-AFNOR

Niamké F, Amusant A, Charpentier J-P, Chaix G, Baissac Y, Boutahar N, Adima A, Kati-Coulibaly S, Jay Allemand C (2011) Relationships between biochemical attributes (non structural carbohydrates and phenolics) and natural durability against fungi in dry teak wood. Ann Forest Sci 68:201211

Obanda DN, Shupe TF, Barnes HM (2008) Reducing leaching of boronbased wood preservatives-a review of research. Bioresource Technol 99:7312-7322

Ouchiyama N, Zhang Y, Omori T, Kodama T (1993) Biodegradation of carbazole by Pseudomonas spp. CA06 and CA10. Biosci Biotech Biochem 57:455-460

Pichelin F, Kamoun C, Pizzi A (1999) Hexamine hardener behaviour: effects on wood glueing, tannin and other wood adhesives. Eur J Wood Wood Prod. 57:305-317
Pizzi A (1994) Advanced wood adhesives technology. CRC Press

Thevenon MF, Pizzi A, Haluk JP (1997) Non-toxic albumin and soja protein borates as ground-contact wood preservatives. Eur J Wood Wood Prod. 55:293-296

Thevenon MF, Tondi G, Pizzi A (2009) High performance tannin resinboron wood preservatives for outdoor end-uses. Eur J Wood Wood Prod. 67:89-93

Thévenon MF, Tondi G, Pizzi A (2010) Environmentally friendly wood preservative system based on polymerized tannin resinboric acid for outdoor applications. Maderas-Cienc Tecnol $12: 253-257$

Tondi G, Wieland S, Lemenager N, Petutschnigg A, Pizzi A, Thevenon MF (2012a) Efficacy of tannin in fixing boron in wood: fungal and termite resistance. Bioresources 7:1238-1252

Tondi G, Palanti S, Wieland S, Thevenon MF, Petutschnigg A, Schnabel $\mathrm{T}$ (2012b) Durability of tannin-boron-treated timber. Bioresources 7: $5138-5151$

Tondi G, Wieland S, Wimmer T, Thevenon MF, Pizzi A, Petutschnigg A (2012c) Tannin-boron preservatives for wood buildings: mechanical and fire properties. Eur J Wood Wood Prod 70:689-696

Tondi G, Thevenon MF, Mies B, Standfest G, Petutschnigg A, Wieland S (2013a) Impregnation of Scots pine and beech with tannin solutions: effect of viscosity and wood anatomy in wood infiltration. Wood Sci Technol 47:615-626

Tondi G, Schnabel T, Wieland S, Petutschnigg A (2013b) Surface properties of tannin treated wood during natural and artificial weathering. Int J Wood Prod 4:150-157

Tondi G, Haurie L, Wieland S, Petutschnigg A, Lacasta A, Monton J (2014) Comparison of disodium octaborate tetrahydrate (DOT) and tannin-boron based formulations as fire retardant for wood structures. Fire Mater 38:381-390

Tondi G, Hu J, Rizzo F, Buh J, Medved S, Petutschnigg A, Thevenon MF (2016) Advanced tannin-boron formulations: Part 1: Weathering properties. Ann Forest Sci (under review)

Williams LH, Amburgey TL. (1985) Protection of wood from decay fungi, subterranean termites, and lyctus beetles by treatment with borates. Forest Prod. Res. Soc. Annual Meeting, Orlando, FL, June, 1985

Zheng W, Wang X, Yu H, Tao X, Zhou Y, Qu W (2011) Global trends and diversity in pentachlorophenol levels in the environment and in humans: a meta-analysis. Environ Sci technol 45:4668-4675 